\title{
Syntheses and photophysical properties of type-II CdSe/ZnTe/ZnS (core/shell/shell) quantum dots $\dagger$
}

\author{
Chiu-Ting Cheng, ${ }^{a}$ Chun-Yen Chen, ${ }^{a}$ Chih-Wei Lai, ${ }^{a}$ Wei-Hsin Liu, ${ }^{a}$ Shih-Chieh Pu, ${ }^{a}$ Pi-Tai Chou, ${ }^{* a}$ \\ Yi-Hsuan Chou ${ }^{b}$ and Hsin-Tien Chiu*b
}

Received 11th March 2005, Accepted 29th June 2005

First published as an Advance Article on the web 15th July 2005

DOI: $10.1039 / \mathrm{b503681j}$

Syntheses of CdSe/ZnTe/ZnS (core/shell/shell) type-II quantum dots (QDs) are reported.

Structural characterization was made via TEM, EDX, XPS and XRD. Photophysical properties were investigated via the interband emission $(\mathrm{CdSe} \rightarrow \mathrm{ZnTe})$ and its associated quantum efficiency as well as relaxation dynamics. In comparison to the weak emission $\left(\Phi_{\mathrm{f}} \sim 4 \times 10^{-3}\right.$ in toluene) of $\mathrm{CdSe} / \mathrm{ZnTe}(3.9 / 0.5 \mathrm{~nm})$, capping $\mathrm{ZnS}$ (0.4 nm in thickness) enhances the $\mathrm{CdSe} \rightarrow \mathrm{ZnTe}$ interband emission by $\sim 30$ fold $\left(\Phi_{\mathrm{f}} \sim 0.12\right)$, whereas the peak wavelength shifts only slightly to the red. By encapsulating dihydrolipoic acid (DHLA), water-soluble CdSe/ZnTe/ZnS QDs were also prepared, and they exhibited an interband emission at $\sim 930 \mathrm{~nm}$ with an emission yield of $\sim 0.1$. Femtosecond pulse excitation $\left(\lambda_{\mathrm{ex}} \sim 1200 \mathrm{~nm}\right)$ measurement estimated a two-photon absorption cross section, $\sigma$, of $\sim 70 \times 10^{-50} \mathrm{~cm}^{4}$ s photon $^{-1}$ for DHLA-capped CdSe/ZnTe/ZnS in water, supporting its suitability for the use as near-infrared (NIR) dyes in biomedical imaging.

\section{Introduction}

Type-II quantum dots (QDs) have both valence and conduction bands in the core lower (or higher) than those in the shell materials. After electronic excitation, one carrier is predominantly confined to the core, while the other is located at the shell. This spatial separation of charge carriers leads to several characteristic differences from the type-I QDs. Particularly, the interband emission is allowable with an energy gap that would be otherwise inaccessible with type-I structures, extending the color-tuning capability even to the near-IR. However, despite well-documented studies of type-I core/shell QDs, ${ }^{1-7}$ studies of type-II QDs are relatively rare. Recently, based on a colloidal template, a seminal work on the chemical syntheses of type-II CdTe/CdSe (core/shell) and $\mathrm{CdSe} / \mathrm{ZnTe}$ (core/shell) QDs using $\mathrm{Cd}\left(\mathrm{CH}_{3}\right)_{2}$ as a $\mathrm{Cd}$ precursor has been reported. ${ }^{8}$ This colloidal template approach is crucial in that it provides both feasibility and versatility toward further chemical modification. Subsequently, we have reported the synthesis of CdSe/ZnTe (core/shell) type-II QDs via a safer precursor, $\mathrm{CdO}$, and studied their corresponding excitedstate relaxation dynamics. ${ }^{9}$ In another approach, $\mathrm{CdTe} / \mathrm{CdSe}$ type-II QDs have been exploited as near-infrared (NIR) dyes for biomedical imaging in living tissue by taking advantage of their great photostability and deeper light penetration. ${ }^{10}$ In view of applications, one disadvantage to using type-II QDs, however, lies in their much weaker quantum efficiency in

\footnotetext{
${ }^{a}$ Department of Chemistry, National Taiwan University, Taipei 106, Taiwan. E-mail: chop@ntu.edu.tw; Fax: 886-2-23695208;

Tel: 886-2-23630231 ext.3988

${ }^{b}$ Department of Applied Chemistry, National Chiao Tung University, Hsinchu 300, Taiwan

$\uparrow$ Electronic supplementary information (ESI) available: Fig. S1: XPS spectra of CdSe/ZnTe and CdSe/ZnTe/ZnS QDs. See http://dx.doi.org/ $10.1039 / \mathrm{b} 503681 \mathrm{j}$
}

general relative to type-I QDs. Since the interband emission originates from the spatially separated $\mathrm{CdSe} \rightarrow \mathrm{ZnTe}$ transition, its associated radiative lifetime is expected to be long. Thus, any radiationless process, such as the floating of hole-carriers to the surface in the case of CdSe/ZnTe QDs, will drastically quench the emission intensity. As an approach to enhancing the quantum efficiency toward NIR applications, we report herein the encapsulation of a third layer with $\mathrm{ZnS}$ to achieve a $\mathrm{CdSe} / \mathrm{ZnTe} / \mathrm{ZnS}$ (core/shell/shell) structure. As shown in Scheme 1, in this case, the conduction band in $\mathrm{ZnTe}$

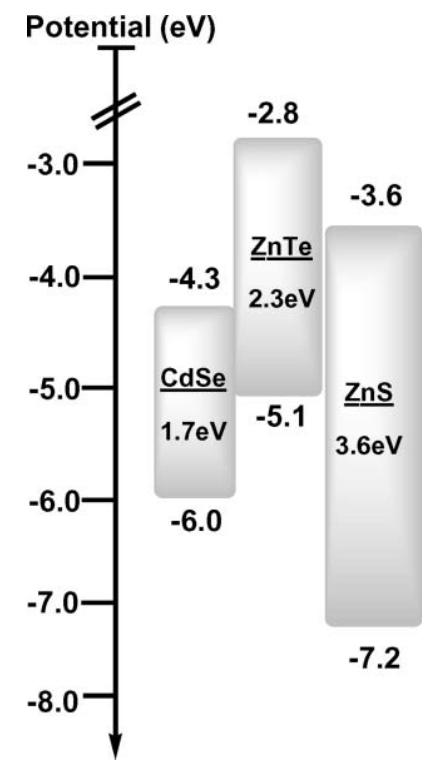

Scheme 1 Plot illustrating the CdSe, ZnTe and $\mathrm{ZnS}$ band offsets alignment in energy (data are taken from ref. 11). Note that the changes of band gap and hence the relative energies in the interfacial regions are neglected in this diagram. 
is well above that in $\mathrm{CdSe}$, while the valence band of $\mathrm{ZnS}$ is below that of $\mathrm{ZnTe}$. Upon excitation, electrons and holes are strictly confined in CdSe and ZnTe, respectively, encapsulated by $\mathrm{ZnS}$. Thus, floating of hole-carriers to the surface $(\mathrm{ZnS})$ can be significantly reduced, resulting in the enhancement of $\mathrm{CdSe} \rightarrow \mathrm{ZnTe}$ interband emission intensity.

Structural characterization of the synthesized CdSe/ZnTe/ ZnS QDs has been made via TEM, EDX, XPS and XRD. Photophysical properties were investigated via the absorption, interband emission ( $\mathrm{CdSe} \rightarrow \mathrm{ZnTe}$ ) and its associated quantum efficiency, as well as relaxation dynamics. In view of applications in biomedical imaging, dihydrolipoic acid (DHLA) encapsulated water-soluble CdSe/ZnTe/ZnS QDs were also prepared and the corresponding two-photon cross section was measured. Details of results and discussion are elaborated as follows.

\section{Experimental}

\section{Chemicals}

Tri- $n$-octylphosphine oxide (TOPO, 99\%, Aldrich), tri- $n$-butylphosphine (TBP, technical grade 98\%, SHOWA), di- $n$-octylamine (DOA, 98\%, ACROS), hexadecylamine (HDA, 90\%, TCI), CdO (99.99\%, Strem), selenium (Se) powder 200 mesh (99.5\%, Aldrich), sulfur (S) powder (99.5\%, Aldrich), tellurium (Te) powder $(99.8 \%, 200$ mesh, Aldrich) and zinc stearate (Riedel-deHaën) were used immediately after receipt.

\section{Preparation procedures}

The CdSe/ZnTe core/shell nanoparticles were prepared according to our previous report. ${ }^{9}$ To obtain the CdSe/ZnTe/ $\mathrm{ZnS}$ core/shell/shell nanoparticles, the precipitated $\mathrm{CdSe} / \mathrm{ZnTe}$ QDs $(0.020 \mathrm{~g})$ were dispersed in TOPO $(2.20 \mathrm{~g})$ and HDA $(1.26 \mathrm{~g})$ before being heated to $190{ }^{\circ} \mathrm{C}$. In addition, $\mathrm{Zn}$ stearate $(0.316 \mathrm{~g})$ was dissolved in $2.5 \mathrm{~mL}$ of TBP upon gentle heating (ca. $80{ }^{\circ} \mathrm{C}$ ). After being cooled to room temperature, the resulting $0.2 \mathrm{M}$ solution was mixed with $2.5 \mathrm{~mL}$ of a $0.2 \mathrm{M}$ solution of $\mathrm{S}$ in TBP. With a syringe pump, this mixture was injected within $1 \mathrm{~h}$ into the reaction flask containing the core/shell nanocrystals at $190-200{ }^{\circ} \mathrm{C}$. After the addition was complete, the crystals were annealed at $190{ }^{\circ} \mathrm{C}$ for an additional 1-1.5 h. CdSe/ZnTe/ZnS QDs of various $\mathrm{ZnS}$ thicknesses could be obtained by adjusting the concentrations of $\mathrm{Zn}$ stearate and $\mathrm{S}$ in $\mathrm{TBP}$ as well as the corresponding injection times. The resulting $\mathrm{CdSe} / \mathrm{ZnTe} / \mathrm{ZnS}$ QDs were further purified by centrifugation and re-precipitating twice from methanol.

The water-soluble CdSe/ZnTe/ZnS nanoparticles were prepared using a stepwise procedure reported by Mattoussi et al. ${ }^{12}$ with a slight modification. Briefly, TBP/TOPO-capped $\mathrm{CdSe} / \mathrm{ZnTe} / \mathrm{ZnS}$ core/shell/shell particles were subsequently exchanged with $20 \mathrm{mg}$ DHLA (freshly prepared from distilled thioctic acid by sodium borohydride reduction) ${ }^{13}$ placed in a reaction vessel. $15 \mathrm{~mL}$ of methanol was added, and the $\mathrm{pH}$ was adjusted to $>10$ with tetramethylammonium hydroxide pentahydrate. Under dark conditions, $10 \mathrm{mg}$ of $\mathrm{CdSe} / \mathrm{ZnTe} /$ $\mathrm{ZnS}$ nanocrystals were dissolved in the mixture, and the vessel was placed under a regular airflow. The mixture was heated under reflux at $65{ }^{\circ} \mathrm{C}$ overnight, and then the reaction was terminated and the mixture allowed to cool to room temperature. The DHLA-capped nanocrystals were then precipitated with diethyl ether. For further purification, methanol was added to dissolve the precipitate, followed by the addition of diethyl ether to reprecipitate the nanocrystals.

\section{Measurements}

The sizes of the QDs were determined with a Hitachi H-7100 transmission electron microscope (TEM). Further characterization of QDs was made by powder X-ray diffraction (XRD, model PANalytical $\mathrm{X}^{\prime}$ Pert PRO) and X-ray photoelectron spectroscopy (XPS, model VG Scientific ESCALAB 250). UV-Vis steady-state absorption and emission spectra were recorded with a Hitachi (U-3310) spectrophotometer and an Edinburgh (FS920) fluorimeter, respectively. The NIR emission spectra were obtained by exciting the sample solution under a front-face excitation configuration using an Ar ion laser (488 or $514 \mathrm{~nm}$, Coherent Innova 90). The emission was then sent through an NIR-configured Fourier-transform interferometer (Bruker Equinox 55) and detected with an NIR sensitive photomultiplier (Hamamatsu model R5509-72) operated at $-80{ }^{\circ} \mathrm{C}$. Details of nanosecond lifetime measurements have been described previously. ${ }^{9}$ IR 125 (Exciton) was used as a standard for the quantum yield $\left(\Phi_{\mathrm{f}}\right)$ measurement. $\Phi_{\mathrm{f}}$ for IR125 was reported to be 0.11 in dimethyl sulfoxide (emission peak wavelength $\sim 910 \mathrm{~nm}$ ). ${ }^{14}$

For the measurement of the two-photon absorption cross section, a mode-locked femtosecond Ti:Sapphire laser (Spectraphysics, $100 \mathrm{fs}, 80 \mathrm{MHz}$ ) pumped Opal (Spectra-physics, $130 \mathrm{fs}$, $80 \mathrm{MHz}$ ) was used as the excitation source. The NIR fluorescence was collected at a direction perpendicular to the pump beam. To minimize the re-absorption effect, the excitation beam was focused as closely as possible to the front wall of the quartz cell. The near-infrared (NIR) emission was measured by a photomultiplier tube (Hamamatzu R5509-72) coupled with a Lock-in Amplifier (Stanford Research System SR830) and a monochromator (Acton, SpectraPro-275) in that the grating was blazed at $1200 \mathrm{~nm}$. The dye 5,10,15,20tetraphenylporphine ( $\mathrm{H}_{2} \mathrm{TPP}$, Aldrich) was used as a standard, for which the two-photon absorption cross section $(\sigma)$ was reported to be $3.5 \mathrm{GM}\left(1 \mathrm{GM}=10^{-50} \mathrm{~cm}^{4} \mathrm{~s}_{\text {photon }}{ }^{-1}\right)$ upon 1200 -nm excitation in toluene. ${ }^{15}$

\section{Results and discussion}

Fig. 1 depicts TEM images and size histograms of CdSe/ZnTe (core/shell) and CdSe/ZnTe/ZnS (core/shell/shell) in which the core/shell (CdSe/ZnTe) QDs are from the same batch. The size histograms of $\mathrm{CdSe} / \mathrm{ZnTe}$ and $\mathrm{CdSe} / \mathrm{ZnTe} / \mathrm{ZnS}$ QDs were established via counting each individual size for 500 particles. Since the $\mathrm{CdSe} / \mathrm{ZnTe} / \mathrm{ZnS}$ QDs were prepared from the same batch of $\mathrm{CdSe} / \mathrm{ZnTe}$, it is reasonable to assume the same core/shell size. As an indirect approach, the thickness of $\mathrm{ZnS}$ can be estimated by the subtraction of $\mathrm{CdSe} / \mathrm{ZnTe}$ size from that of the CdSe/ZnTe/ZnS prepared. For the QDs shown in Fig. 1, the diameters of CdSe/ZnTe and $\mathrm{CdSe} / \mathrm{ZnTe} / \mathrm{ZnS}$ were measured to be in an average of 5.0 and $5.8 \mathrm{~nm}$, respectively. Accordingly, the thickness of $\mathrm{ZnS}$ was estimated to be $0.4 \mathrm{~nm}$. 
(a)

(b)
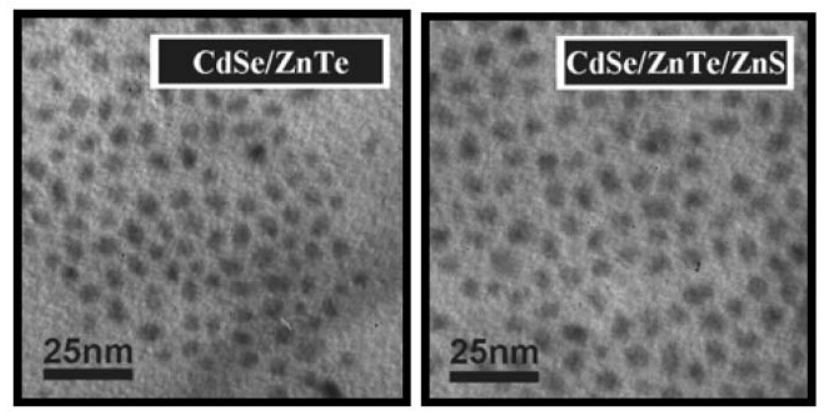

(c)

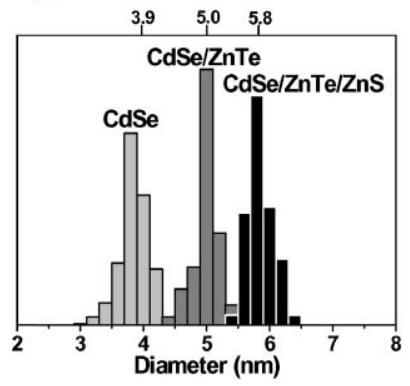

(d)

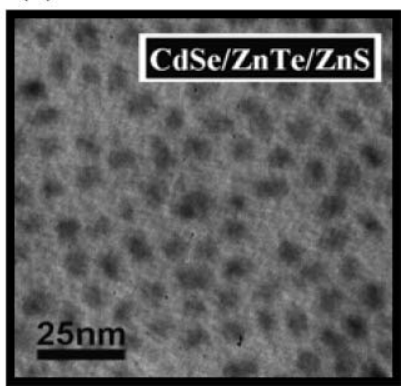

Fig. 1 TEM images of the samples with average diameter of $5.0 \mathrm{~nm}$ for CdSe/ZnTe QDs (a) and $5.8 \mathrm{~nm}$ for CdSe/ZnTe/ZnS QDs (b). (c) Size histograms for the samples in which the histograms were constructed by counting 500 particles in each sample. (d) CdSe/ZnTe/ $\mathrm{ZnS}$ QDs of $6.6 \mathrm{~nm}(0.8 \mathrm{~nm}$ thickness in $\mathrm{ZnS})$.

Considering that TEM generally provides insufficient contrast at the edges of nanoparticles, the calculated $\mathrm{ZnS}$ thickness could be subject to $\sim 10-15 \%$ uncertainty.

The corresponding composition of CdSe/ZnTe/ZnS QDs was characterized by energy dispersive spectroscopy (EDX). As shown in Fig. 2(a), the appearance of the $\mathrm{S}$ peak at $2.33 \mathrm{keV}$, in combination with the increase of the ratio for $\mathrm{Zn}$ vs. Te from $\mathrm{CdSe} / \mathrm{ZnTe}$ to $\mathrm{CdSe} / \mathrm{ZnTe} / \mathrm{ZnS}$, may indirectly support the formation of the $\mathrm{ZnS}$ shell, although the possibility of alloy formation can not be ruled out. Furthermore, as shown in Fig. 2(b), comparing the XRD pattern of the CdSe/ZnTe core/shell, two sets of peaks at faces (100), (002), (101) and (110), (103), (112) in CdSe/ZnTe/ZnS QDs revealed the same spectral features, with a slight shift to lower scattering angle for the (110), (103), (112) peaks. Owing to a similar XRD pattern for these two sets of peaks, the formation of an alloy upon encapsulating $\mathrm{ZnS}$ is not likely. Nevertheless, similar to the results of EDX, the X-ray data could not definitely conclude a core/shell/shell structure.

In an attempt to extract more composition information we have further made efforts to perform XPS analyses. However, as depicted in the ESI, $\dagger$ our results revealed negligibly small differences in XPS peaks between CdSe/ZnTe and CdSe/ZnTe/ $\mathrm{ZnS}$ systems for $\mathrm{Cd}, \mathrm{Zn}$, Se and Te elements. Such results may not be surprising; for the case of $\mathrm{Cd} 3 \mathrm{~d}_{5 / 2}$ in $\mathrm{CdSe}$ and $\mathrm{CdTe}$, photoelectron peaks are expected to be located at $404.8 \mathrm{eV}^{16}$ (or $405.0 \mathrm{eV}^{17}$ ) and $405.0 \mathrm{eV}^{16}$ (or $404.8 \mathrm{eV}^{17}$ ), respectively. Our results of $\sim 405.4 \mathrm{eV}$, within experimental uncertainty, can not be definitely distinguished. Alternatively,

(a)

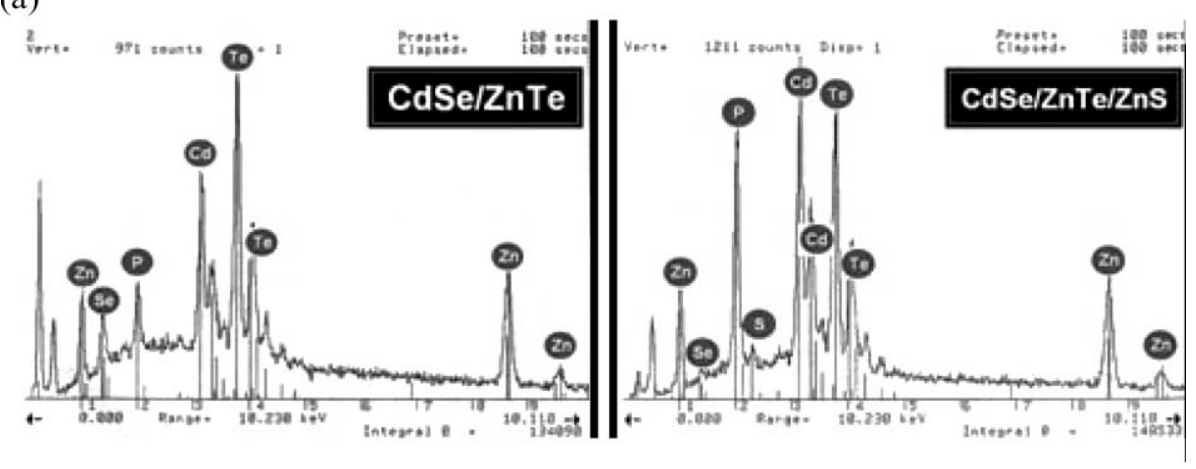

(b)
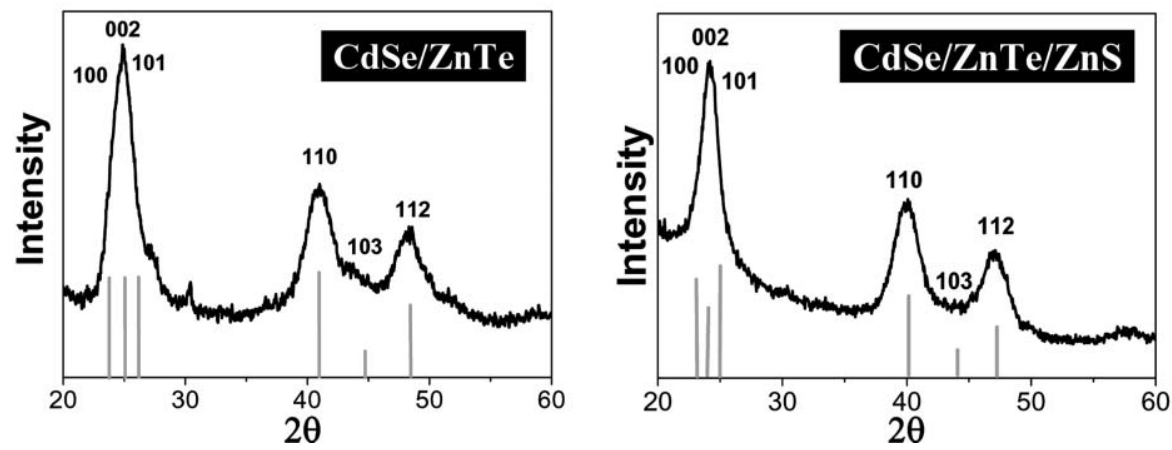

Fig. 2 (a) Energy dispersive spectroscopy (EDX) characterization of CdSe/ZnTe core/shell QDs (left) and CdSe/ZnTe/ZnS core/shell/shell QDs. (b) X-Ray diffraction (XRD) data of CdSe/ZnTe core/shell QDs (left) and CdSe/ZnTe/ZnS core/shell/shell QDs (right). 
if one focuses on the Te $3 d_{5 / 2}$ state, the resulting Te peak was located at $572.8 \mathrm{eV}$ for both $\mathrm{CdSe} / \mathrm{ZnTe}$ and $\mathrm{CdSe} / \mathrm{ZnTe} / \mathrm{ZnS}$ systems (see ESI $\dagger$ ). In comparison, the corresponding peak for $\mathrm{ZnTe}$ is expected to be at $572.9 \mathrm{eV},{ }^{18}$ which is similar to that of CdTe of $572.7 \mathrm{eV} .^{18}$ Thus, the resolution of our current system is not sufficiently high enough to resolve the origin of the $572.8 \mathrm{eV}$ peak. Similarly, the $\mathrm{Zn} 2 \mathrm{p}_{3 / 2}$ signal in $\mathrm{ZnTe}$, predicted to be at $1021.4 \mathrm{eV},{ }^{16}$ is also indistinguishable from that of $\mathrm{ZnS}\left(1021.4 \mathrm{eV}^{16}\right)$, so that our result of $\sim 1021.4 \mathrm{eV}$ can not be unambiguously assigned to either. Nevertheless there is no signal at $1022.0 \mathrm{eV}^{17}$ for $\mathrm{ZnSe}$, the results of which, in part, support the lack of alloy formation between CdSe and $\mathrm{ZnTe}$ layers in the $\mathrm{CdSe} / \mathrm{ZnTe} / \mathrm{ZnS}$ system.

In the angle-resolved XPS approach, the peak intensity ratio for elements of the core and the shell as a function of the electron takeoff angle may serve as a tool for extracting geometrical information about the nanoparticles. ${ }^{19}$ For example, Piyakis et al. $^{20}$ have reported the XPS analysis of spherical $\mathrm{Cu}$ nanoclusters by using angle-resolved XPS in combination with Monte Carlo simulation. ${ }^{20}$ We have thus made extensive efforts in the angle-tuning studies. Unfortunately, negligible electron-takeoff-angle dependence was observed for the ratio of peak intensities. This result can be tentatively rationalized by the rather thin layer for both the $\mathrm{ZnTe}(0.5 \mathrm{~nm})$ and $\mathrm{ZnS}(0.4 \mathrm{~nm})$ shell in comparison to the CdSe core (3.9 $\mathrm{nm}$ in diameter), so that the peak intensities for $\mathrm{Zn}$ and $\mathrm{Te}$ ( or $\mathrm{S}$ ) in the two shell layers are not sensitive enough to the angle tuning. Consequently, in the following section. we will focus on absorption and luminescence spectroscopy to substantially support our viewpoint of $\mathrm{CdSe} / \mathrm{ZnTe} / \mathrm{ZnS}$ formation.

The absorption and emission spectra of the three types of QDs are shown in Fig. 3. Apparently, despite the significant differences in absorption and emission spectra from $\mathrm{CdSe}$ $\left(\lambda_{\mathrm{em}} \sim 570 \mathrm{~nm}\right)$ to $\mathrm{CdSe} / \mathrm{ZnTe}\left(\lambda_{\mathrm{em}} \sim 865 \mathrm{~nm}\right)$, only slight red

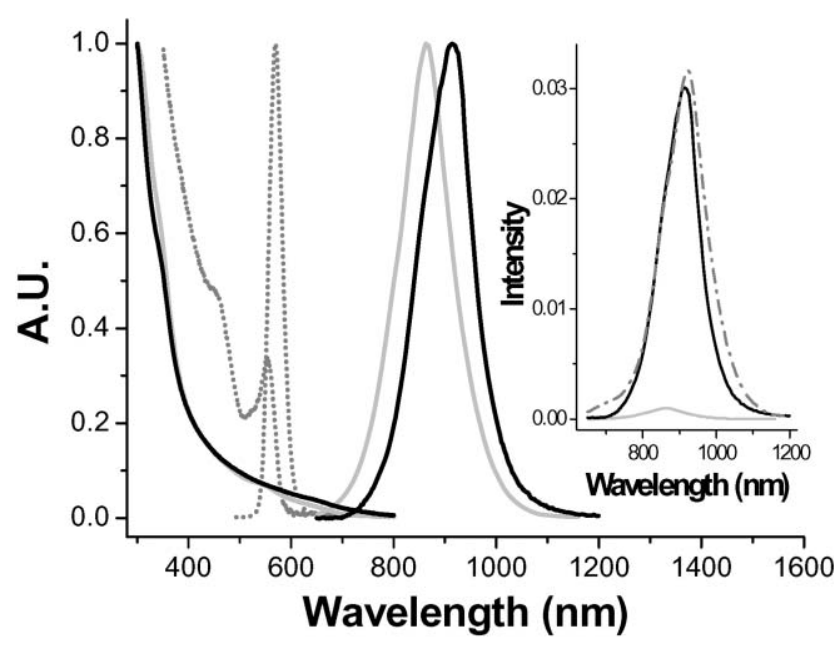

Fig. 3 The normalized absorption and emission spectra of the CdSe core QDs (3.9 nm, dotted line), CdSe/ZnTe core/shell QDs $(5.0 \mathrm{~nm}$, light grey) and CdSe/ZnTe/ZnS core/shell/shell QDs (5.8 nm, black) QDs in toluene; see Table 1 for the corresponding diameters. Inset: The emission intensity of CdSe/ZnTe/ZnS QDs (black: $5.8 \mathrm{~nm}$, dashed line: $6.6 \mathrm{~nm}) v s$, that of $\mathrm{CdSe} / \mathrm{ZnTe}$ QDs $(5.0 \mathrm{~nm}$, light grey) under identical experimental conditions. shifting in both absorption and emission spectral features was observed from CdSe/ZnTe to CdSe/ZnTe/ZnS ( $\left.\lambda_{\mathrm{em}} \sim 915 \mathrm{~nm}\right)$. Note that in general an alloy composite would give a blue shift in both emission and absorption edge. ${ }^{21}$ Thus, the red shift in both absorption and emission spectra indirectly proves the $\mathrm{CdSe} / \mathrm{ZnTe} / \mathrm{ZnS}$ (core/shell/shell) structure rather than alloy formation. Furthermore, it seems unlikely that $\mathrm{ZnTe}$ and $\mathrm{ZnS}$ would form an alloy because of their lattice mismatch (the CdSe lattice $(6.05 \AA)$ is about $12 \%$ larger than that of ZnS (5.41 $\AA$ ). ${ }^{21}$ The resulting emission energy gap may be rationalized by the energy diagram depicted in Scheme 1, although the corresponding energetics refer to the bulk materials. As depicted in Scheme 1, the lowest energy gap should be ascribed to the $\mathrm{ZnTe} \rightarrow \mathrm{CdSe}$ interband transition $(\sim 0.8 \mathrm{eV})$, while the interband transition between $\mathrm{ZnTe}$ and $\mathrm{ZnS}$ is much higher in energy $(\sim 1.5 \mathrm{eV})$ and may have negligible influence on the lower lying transitions.

Table 1 lists the room-temperature emission properties for all three types of QDs with the same core size (and same thickness for $\mathrm{ZnTe}$ ). While CdSe gave rise to a ligand (TOPO) confined 570-nm emission with quantum efficiency as high as 0.52, the CdSe/ZnTe $865-\mathrm{nm}$ emission is relatively much weaker, with a quantum yield $\left(\Phi_{\mathrm{f}}\right)$ estimated to be $4.0 \times 10^{-3}$. Lifetimes $\left(\tau_{\mathrm{f}}\right)$ for $\mathrm{CdSe}$ and $\mathrm{CdSe} / \mathrm{ZnTe}$ were further measured to be 35 and $55 \mathrm{~ns}$, respectively. The radiative decay rates, $k_{\mathrm{r}}$, calculated according to $k_{\mathrm{r}}=\Phi_{\mathrm{f}} / \tau_{\mathrm{f}}$, were then deduced to be $1.5 \times 10^{7} \mathrm{~s}^{-1}(\mathrm{CdSe})$ and $7.3 \times 10^{4} \mathrm{~s}^{-1}(\mathrm{CdSe} / \mathrm{ZnTe})$. Accordingly, the nonradiative decay rates were deduced to be $1.4 \times 10^{7} \mathrm{~s}^{-1}$ and $1.8 \times 10^{7} \mathrm{~s}^{-1}$ for $\mathrm{CdSe}$ and $\mathrm{CdSe} / \mathrm{ZnTe}$, respectively. The $\sim 200$-fold smaller radiative lifetime for the $\mathrm{CdSe} \rightarrow \mathrm{ZnTe}$ emission is attributed to the spatially separated electron-hole recombination. As a result, despite the same magnitude of radiationless decay rates in $\mathrm{CdSe} / \mathrm{ZnTe} \mathrm{QDs}$, its quantum efficiency is much lower than that of CdSe.

A drastic increase of the $\mathrm{CdSe} \rightarrow \mathrm{ZnTe}$ interband emission intensity was observed after encapsulating $\mathrm{ZnS}$. The quantum efficiency was increased to 0.12 , which is $\sim 30$ times as large as that of the CdSe/ZnTe QDs. More importantly, the peak wavelength, i.e. the associated $\mathrm{CdSe} \rightarrow \mathrm{ZnTe}$ energy gap, changed only slightly, with a slight bathochromic shift from 865 to $915 \mathrm{~nm}$, and hence an energy shift of $\sim 1.8 \mathrm{kcal} \mathrm{mol}^{-1}$. The small variation of the peak wavelength also supports the aforementioned viewpoint that coating $\mathrm{ZnS}$ only affected slightly the $\mathrm{CdSe} \rightarrow \mathrm{ZnTe}$ transition due to the well separated upper and lower energy levels in the conduction and valence bands, respectively, for $\mathrm{ZnS}$. The increase of quantum efficiency also correlates well with the increase of the observed lifetime to as large as $\sim 1.2 \mu \mathrm{s}$. Accordingly, the radiative

Table 1 Room-temperature photophysical properties for CdSe, $\mathrm{CdSe} / \mathrm{ZnTe}$ and CdSe/ZnTe/ZnS QDs

\begin{tabular}{lllrl}
\hline & Size/nm & PL $\left(\lambda_{\text {max }}\right) / \mathrm{nm}$ & $\tau_{\mathrm{f}} / \mathrm{ns}$ & $\Phi_{\mathrm{f}}$ \\
\hline $\mathrm{CdSe}^{a}$ & 3.9 & 570 & 35 & 0.52 \\
$\mathrm{CdSe}_{\mathrm{ZnTe}}{ }^{a}$ & 5.0 & 865 & 55 & 0.004 \\
$\mathrm{CdSe} / \mathrm{ZnTe} / \mathrm{ZnS}{ }^{a}$ & 5.8 & 915 & 1200 & 0.12 \\
$\mathrm{CdSe} / \mathrm{ZnTe} / \mathrm{ZnS}{ }^{a}$ & 6.6 & 920 & 1210 & 0.12 \\
$\mathrm{CdSe} / \mathrm{ZnTe} / \mathrm{ZnS}{ }^{b}$ & ${ }^{c}$ & 930 & 950 & 0.10
\end{tabular}

${ }^{a}$ TOPO-capped QDs in toluene. ${ }^{b}$ DHLA-capped QDs in water $(\mathrm{pH} \sim 7.0),{ }^{c}$ Not available due to the aggregation, see text. 
decay rate was calculated to be $1.0 \times 10^{5} \mathrm{~s}^{-1}$, which, within experimental error, is similar to that of $\mathrm{CdSe} / \mathrm{ZnTe}$, indicating negligible interference from $\mathrm{ZnS}$; rather, $\mathrm{ZnS}$ plays a key role in introducing a barrier to confine holes in $\mathrm{ZnTe}$ (see Scheme 1). This viewpoint can be further supported by the deduced radiationless decay rate of $7.3 \times 10^{5} \mathrm{~s}^{-1}$. The rather small radiationless decay rate constant in $\mathrm{CdSe} / \mathrm{ZnTe} / \mathrm{ZnS}$ QDs is plausibly due to the hole trapping in $\mathrm{ZnTe}$ so that fewer holes are present on the outer surface. We further made a synthetic attempt to increase the thickness of $\mathrm{ZnS}$ from $\sim 0.4$ to $\sim 0.8 \mathrm{~nm}$. The increase of average size from $\sim 5.8$ to $6.6 \mathrm{~nm}$ can be seen from Fig. 1(d). As depicted in the inset of Fig. 3, the emission peak wavelength only slightly shifted from $915 \mathrm{~nm}$ $(0.4 \mathrm{~nm} \mathrm{ZnS})$ to $920 \mathrm{~nm}(0.8 \mathrm{~nm} \mathrm{ZnS})$, with $<3 \%$ increase of quantum efficiency (see Table 1). Further increase of $\mathrm{ZnS}$ thickness to $\sim 1.1 \mathrm{~nm}$ resulted in negligible changes for both peak wavelength and emission intensity (not shown here), indicating that $\mathrm{ZnS}$ with a thickness of $\geqslant 0.4 \mathrm{~nm}$ should have a good passivation on $\mathrm{ZnTe}$.

Fig. 4 shows the 930-nm emission $\left(\Phi_{\mathrm{f}} \sim 0.10\right)$ of watersoluble, i.e. DHLA-capped, $\mathrm{CdSe} / \mathrm{ZnTe} / \mathrm{ZnS}$ QDs. In comparison to its precursor, i.e. TOPO-capped $\mathrm{CdSe} / \mathrm{ZnTe} / \mathrm{ZnS}$ QDs $\left(\lambda_{\max } \sim 915 \mathrm{~nm}\right.$ in toluene), the $\sim 15 \mathrm{~nm}$ bathochromic shift of the emission peak is possibly due to the perturbation of different solvent polarities. Nevertheless, one can not eliminate subtle changes of size distributions during chemical modification. Unfortunately, TEM revealed aggregation of DHLA-capped CdSe/ZnTe/ZnS QDs, which prevented further differentiation between the TOPO- and DHLA-capped QDs in size distribution. Measurements of the two-photon absorption cross section were carried out by femtosecond pulse excitation $\left(\lambda_{\mathrm{ex}} \sim 1200 \mathrm{~nm}, 130 \mathrm{fs}\right)$. The spectral feature of the emission upon 1200-nm excitation was qualitatively the same as that of one-photon excitation (see Fig. 5). As shown in Fig. 5, the plot of $930-\mathrm{nm}$ peak intensity vs. the square of excitation power

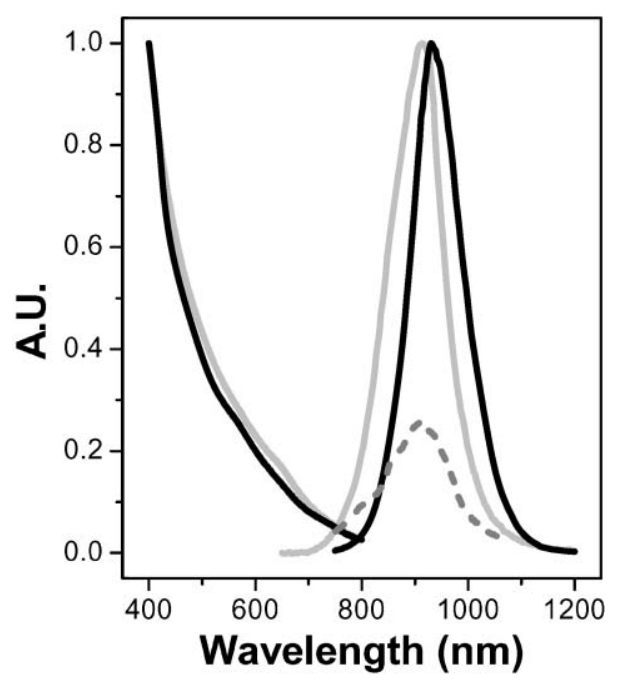

Fig. 4 The absorption and emission spectra (light grey) of TOPOcapped $\mathrm{CdSe} / \mathrm{ZnTe} / \mathrm{ZnS}$ QDs a in toluene and of DHLA-capped $\mathrm{CdSe} / \mathrm{ZnTe} / \mathrm{ZnS}$ QDs in water (pH 7) (black) synthesized from batch a. The dashed curve shows the emission of DHLA-capped $\mathrm{CdSe} / \mathrm{ZnTe} / \mathrm{ZnS}$ QDs in water excited by $1200-\mathrm{nm}$ laser pulses.

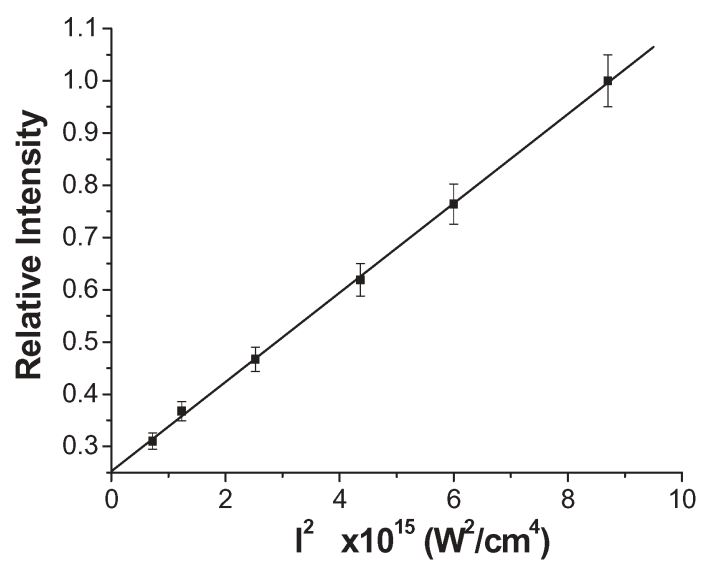

Fig. 5 Plot of 930-nm peak intensity $(I)$ for DHLA-capped $\mathrm{CdSe} / \mathrm{ZnTe} / \mathrm{ZnS}$ as a function of the square of excitation power $\left(\lambda_{\mathrm{ex}} \sim 1200 \mathrm{~nm}\right)$.

showed sufficiently linear behavior, supporting the origin of emission from a two-photon absorption process.

Taking the absorption extinction coefficient for CdSe (3.9 $\mathrm{nm}$ ) to be $2.2 \times 10^{5} \mathrm{M}^{-1} \mathrm{~cm}^{-1}, 22$ the DHLA-capped $\mathrm{CdSe} / \mathrm{ZnTe} / \mathrm{ZnS}$ concentration was calculated as $5.8 \times 10^{-7} \mathrm{M}$ in this study. Upon preparing the same concentration for both DHLA-capped CdSe/ZnTe/ZnS QDs and $\mathrm{H}_{2} \mathrm{TPP}$, the twophoton excited emission intensity for DHLA-capped CdSe/ $\mathrm{ZnTe} / \mathrm{ZnS}$ QDs was calculated to be $\sim 20$-fold higher than that of $\mathrm{H}_{2}$ TPP. Knowing $\sigma$ to be $3.5 \mathrm{GM}$ for $\mathrm{H}_{2} \mathrm{TPP},{ }^{15} \sigma$ for $\mathrm{CdSe} / \mathrm{ZnTe} / \mathrm{ZnS}$ QDs was estimated to be $\sim 70 \mathrm{GM}$.

\section{Conclusion}

In conclusion, synthesis of $\mathrm{CdSe} / \mathrm{ZnTe} / \mathrm{ZnS}$ (core/shell/shell) type-II QDs from CdSe/ZnTe has been achieved. In comparison to that of type-II CdSe/ZnTe, although the addition of $\mathrm{ZnS}$ only changed the interband emission peak wavelength slightly, due to the quantum confinement for the $\mathrm{CdSe} \rightarrow \mathrm{ZnTe}$ interband emission, type-II CdSe/ZnTe/ZnS gives rise to $\sim 30$-fold enhancement of the quantum efficiency ( $\left.\Phi_{\mathrm{f}} \sim 0.12\right)$. By encapsulating DHLA, water-soluble $\mathrm{CdSe} /$ $\mathrm{ZnTe} / \mathrm{ZnS}$ (3.9/0.5/0.4 nm) was prepared, and such QDs exhibited an interband emission at $\sim 930 \mathrm{~nm}$ with a fluorescence yield of $\sim 0.1$. Femtosecond pulse $\left(\lambda_{\mathrm{ex}} \sim 1200 \mathrm{~nm}\right)$ excitation measurement derives a two-photon absorption cross section, $\sigma$, of $\sim 70 \mathrm{GM}$ for the latter QDs, supporting their suitability for use as near-IR dyes for biomedical imaging by taking advantage of their great photostability and deep light penetration.

\section{References}

1 A. P. Alivisatos, Science, 1996, 271, 933.

2 M. Danek, K. F. Jensen, C. B. Murray and M. G. Bawendi, Chem. Mater., 1996, 8, 173.

3 B. O. Dabbousi, J. Rodriguez-Viejo, F. V. Mikulec, J. R. Heine, H. Mattoussi, R. Ober, K. F. Jensen and M. G. Bawendi, J. Phys. Chem. B, 1997, 101, 9463.

4 M. Nirmal and L. Brus, Acc. Chem. Res., 1999, 32, 407.

5 H. Mattoussi, J. M. Mauro, E. R. Goodman, G. P. Anderson, V. C. Sundar, F. V. Mikulec and M. G. Bawendi, J. Am. Chem. Soc., 2000, 122, 12142. 
6 D. V. Talapin, A. L. Rogach, A. Kornowski, M. Haase and H. Weller, Nano Lett., 2001, 1, 207.

7 P. Reiss, J. Bleuse and A. Pron, Nano Lett., 2002, 2, 781.

8 S. Kim, B. Fisher, H. J. Eisler and M. G. Bawendi, J. Am. Chem. Soc., 2003, 125, 11466.

9 C. Y. Chen, C. T. Cheng, J. K. Yu, S. C. Pu, Y. M. Cheng, P. T. Chou, Y. H. Chou and H. T. Chiu, J. Phys. Chem. B, 2004, 108, 10687.

10 S. Kim, Y. T. Lim, E. G. Soltesz, A. M. De Grand, J. Lee, A. Nakayama, J. A. Parker, T. Mihaljevic, R. G. Laurence, D. M. Dor, L. H. Cohn, M. G. Bawendi and J. V. Frangioni, Nat. Biotechnol., 2004, 22, 93.

11 S. J. Pearton, Wide Bandgap Semiconductors, William Andrew Publishing, New York, 2000, p. 9.

12 H. Mattoussi, J. M. Mauro, E. R. Goldman, G. P. Anderson, V. C. Sundar, F. V. Milkulec and M. G. Bawendi, J. Am. Chem. Soc., 2000, 122, 12142.

13 I. C. Gunsalus, L. S. Barton and W. Gruber, J. Am. Chem. Soc., $1956,78,1763$.
14 R. C. Benson and H. A. Jues, J. Chem. Eng. Data., 1977, 22, 379.

15 A. Karotki, M. Drobizhev, M. Kruk, C. Spangler, E. Nickel and N. Mamardashvili, J. Opt. Soc. Am. B, 2003, 20, 321.

16 D. Briggs and M. P. Seah, Practical surface analysis by Auger and $X$-ray photoelectron spectroscopy, John Wiley \& Sons, New York, 2nd edn., 1993, vol. 1.

17 C. D. Wagner, W. M. Riggs, L. E. Davis, J. F. Moulder and G. E. Muilenberg, Handbook of X-Ray Photoelectron Spectroscopy, Physical Electronics Division, Perkin-Elmer Corporation, Minnesota, 1979.

18 H. Ebert, M. Knecht, M. Muhler, O. Helmer and W. Bensch, J. Phys. Chem., 1995, 99, 3326.

19 I. Tunc, S. Suzer, M. A. Correa-Duarte and L. M. Liz-Marzan, J. Phys. Chem. B, 2005, 109, 7597.

20 K. N. Piyakis, D.-Q. Yang and E. Sacher, Surf. Sci., 2003, 536, 139.

21 M. A. Malik, P. O’Brien and N. Revaprasadu, Chem. Mater., 2002, 14, 2004.

22 W. W. Yu, L. Qu, W. Guo and X. Peng, Chem. Mater., 2003, 15, 2854. 